\title{
Prevention of leukocyte migration to inflamed skin with a novel fluorosugar modifier of cutaneous lymphocyte-associated antigen
}

\author{
Charles J. Dimitroff, Thomas S. Kupper, and Robert Sackstein
}

Harvard Skin Disease Research Center, Department of Dermatology, Brigham and Women's Hospital, Harvard Medical School, Boston, Massachusetts, USA

\begin{abstract}
E-selectin and P-selectin on dermal postcapillary venules play critical roles in the migration of effector T cells into inflamed skin. P-selectin glycoprotein ligand-1 (PSGL-1) modified by $\alpha 1,3$-fucosyltransferase is the principal selectin ligand on skin-homing $\mathrm{T}$ cells and is required for effector $\mathrm{T}$ cell entry into inflamed skin. We have previously shown that a fluorinated analog of $N$-acetylglucosamine peracetylated-4-fluorinated-D-glucosamine (4-F-GlcNAc), inhibits selectin ligand expression on human T cell PSGL-1. To analyze 4-F-GlcNAc efficacy in dampening effector T cell migration to inflamed skin, we elicited allergic contact hypersensitivity (CHS) reactions in mice treated with 4-F-GlcNAc. We also investigated 4-F-GlcNAc efficacy on lymphocyte E-selectin ligand expression in LNs draining antigen-sensitized skin and on other immunological processes requisite for CHS responses. Our results showed that 4-F-GlcNAc treatment attenuated lymphocyte E-selectin ligand expression in skin-draining LNs and prevented CHS reactions. Significant reductions in inflammatory lymphocytic infiltrate were observed, while pathways related to antigenic processing and presentation and naive $T$ cell recognition within skin-draining $L N s$ were unaffected. These data indicate that 4-F-GlcNAc prevents CHS by inhibiting selectin ligand activity and the capacity of effector $\mathrm{T}$ cells to enter antigen-challenged skin without affecting the afferent phase of CHS.
\end{abstract}

J. Clin. Invest. 112:1008-1018 (2003). doi:10.1172/JCI200319220.

\section{Introduction}

Migration of effector $\mathrm{T}$ cells into inflamed skin is a process regulated, in part, by the coordinated and inducible expression of dermal endothelial E-selectin and P-selectin, and of the lymphocyte selectin ligand P-selectin glycoprotein ligand-1 (PSGL-1) (1-7). Furthermore, PSGL-1 glycosylated by the $\alpha 1,3$-fucosyltransferases FucTIV and FucTVII (8-13), and by core $2 \beta 1,6-N$-acetylglucosaminyltransferase (C2GlcNAcT-1) (14-17), confers E-selectin- and P-selectin-binding activity, which is critical for effector $\mathrm{T}$ cell entry into inflamed skin. The precise expression of these glycosylations on human T cell PSGL-1 helps to define the

Received for publication June 6, 2003, and accepted in revised form August 5, 2003.

Address correspondence to: Charles J. Dimitroff, Harvard Institutes of Medicine, Room 650, 77 Avenue Louis Pasteur, Boston, Massachusetts 02115, USA. Phone: (617) 525-5602; Fax: (617) 525-5571; E-mail: cdimitroff@rics.bwh.harvard.edu. Conflict of interest: The authors have declared that no conflict of interest exists.

Nonstandard abbreviations used: P-selectin glycoprotein ligand-1 (PSGL-1); $\alpha 1,3$-fucosyltransferase IV (FucTIV); $\alpha 1,3$-fucosyltransferase VII (FucTVII); core $2 \beta 1,6-N$-acetylglucosaminyltransferase (C2GlcNAcT-1); cutaneous lymphocyteassociated antigen (CLA); $N$-acetylglucosamine (GlcNAc); peracetylated-4-fluorinated-D-glucosamine (4-F-GlcNAc); contact hypersensitivity (CHS); high endothelial venule (HEV); Langerhans cell (LC); phycoerythrin (PE); 2,4-dinitrofluorobenzene (DNFB); alkaline phosphatase (AP); mean channel fluorescence (MCF); hyaluronic acid (HA).
E-selectin-binding structure as cutaneous lymphocyteassociated antigen (CLA) and to distinguish human T cells that have the capacity to enter skin (18-21). CLA expression on effector $\mathrm{T}$ cells is, therefore, an important target for the development of therapeutic strategies to selectively control cutaneous lymphocytic tropism associated with allergic dermatitis, atopic dermatitis, psoriasis, and cutaneous lymphomas.

Our recent data show that modulation of CLA structure and selectin-binding function as natively expressed on human $\mathrm{T}$ cells could alter the capacity of effector $\mathrm{T}$ cells to migrate to inflamed skin (18). In this study, the potential value of a fluorinated analog of $N$-acetylglucosamine (GlcNAc) peracetylated-4-fluorinated-D-glucosamine (4-F-GlcNAc), as a potent and relatively nontoxic metabolic inhibitor of CLA expression is demonstrated (18). 4-F-GlcNAc incorporates into growing poly- $N$-acetyllactosamine chains on PSGL- 1 and blocks the formation of terminal sialyl Lewis X structures, inhibiting CLA expression and preventing human $\mathrm{CLA}^{+} \mathrm{T}$ cell-binding interactions with endothelial E- and P-selectin $(18,22,23)$. At glycosylation-inhibitory concentrations, 4-F-GlcNAc action does not appear to affect lymphocyte metabolism relating to cell growth, protein synthesis, or other biological functions (18).

Allergic contact hypersensitivity (CHS) is a model of cutaneous inflammation that is critically dependent on effector T cell PSGL-1 decorated by FucTIV/VII and C2GlcNAc-T1 and on dermal endothelial selectins for 
elicitation of the inflammatory response $(1-8,11-17)$. Thus, we postulated that metabolic modulation of effector $\mathrm{T}$ cell E-selectin ligand synthesis with 4-F-GlcNAc would reduce the elicitation of allergic CHS responses. In this report, we performed allergic CHS experiments to test the anti-inflammatory efficacy of 4-F-GlcNAc and to examine 4-F-GlcNAc efficacy on immunological processes required for $\mathrm{CHS}$ responses. Results from these studies suggest that 4-F-GlcNAc at well-tolerated doses inhibits effector lymphocyte E-selectin ligand synthesis and attenuates the effector phase of allergic CHS. In contrast, early immunological events that orchestrate antigen processing and presentation to naive $T$ cells appear to be unaffected by 4-F-GlcNAc treatment. Disruption of E-selectin ligand expression on skin-homing effector $T$ cells represents an attractive treatment strategy, supporting the candidacy of 4-F-GlcNAc as a potential therapeutic agent for preventing dermatopathological trafficking of lymphocytes.

\section{Methods}

Mice. Six- to 8-week old C57BL/6 mice were purchased from The Jackson Laboratory (Bar Harbor, Maine, USA) and housed and monitored in a viral antibodyfree/specific pathogen-free barrier animal facility in the Harvard Institutes of Medicine. C57BL/6 mice homozygous deficient for FucTIV and/or FucTVII were generously provided by John Lowe (University of Michigan, Ann Arbor, Michigan, USA). FucTIV/VII- ${ }^{--}$ or FucTVII ${ }^{-/-}$mice between 6 and 12 weeks old were a used as negative controls for CHS experiments and T cell selectin-binding experiments (8-13).

Flow cytometry. Flow cytometric analysis was performed on cultured murine leukocytes or leukocytes isolated from skin-draining LNs using both direct and indirect immunofluorescence staining approaches. All cells used for these experiments were washed twice with cold $\mathrm{PBS} / 2 \% \mathrm{FBS}$ and suspended at $10^{7}$ per milliliter PBS/1\% FBS. Anti-murine CD4 mAb (clone L3T4), anti-murine $\mathrm{CD} 43 \mathrm{mAb}$ (clone 1B11), $\mathrm{\kappa}$ anti-murine CD8b.2 (clone Ly-3.2) or anti-murine CD11c mAb (clone HL3), anti-murine CD18 mAb (clone GAME-46) (all mAb's from BD Biosciences, San Jose, California, USA), or appropriate isotype-matched control $\mathrm{Ab}$ 's were incubated with cells for 30 minutes on ice. Following two washes with PBS $/ 2 \%$ FBS, cells were resuspended in PBS $/ 1 \%$ FBS and fluorochrome-conjugated secondary Ab's $(2 \mu \mathrm{l})$ and incubated for 30 minutes on ice. Cells were washed twice with PBS/2\% FBS and resuspended in PBS, and flow cytometry was performed on a FACScan apparatus equipped with an argon laser tuned at $488 \mathrm{~nm}$ (Becton Dickinson Immunocytometry Systems, San Jose, California, USA).Cells stained with relevant isotype-matched $A b$ 's or autofluorescent cells were subtracted from positive cell staining with test $\mathrm{Ab}$ 's, to control for specificity of test $\mathrm{Ab}$ 's and to avoid false-positive results.

Immunohistochemistry. For analysis of leukocyte infiltrate in inflamed ears following micrometer measurements of CHS reactivity, ears were resected, placed in
$10 \%$ formalin, embedded in paraffin, and sectioned for $\mathrm{H} \& \mathrm{E}$ staining or anti-murine CD3 staining. For anti-murine $\mathrm{CD} 3$ staining, ear sections $(4 \mu \mathrm{m})$ were blocked in $3 \% \mathrm{H}_{2} \mathrm{O}_{2}$ and treated with type 24 protease (0.1\% in PBS; Sigma Chemical Co., St. Louis, Missouri, USA) for 10 minutes at room temperature. Sections were incubated with rabbit anti-CD3 polyclonal $\mathrm{Ab}$ (1:300) (DakoCytomation Inc., Carpinteria, California, USA) for 30 minutes and then HRP-conjugated secondary Ab (Dako EnVision systems; DakoCytomation) for 30 minutes. Sections were then developed with Vector NovaRED substrate (Vector Laboratories Inc., Burlingame, California, USA) and counterstained with hematoxylin. Negative controls were performed in parallel to every experiment, wherein tissue sections were stained with HRP-conjugated secondary $\mathrm{Ab}$ alone and/or developed with chromagen alone and represented background staining. At $\times 200$ magnification, $\mathrm{CD}^{+}$cells (red-stained cells) were counted from the thickest regions of ear skin and expressed as mean \pm SD from eight fields of view per section (three slides per specimen for two experiments).

Generation of murine selectin-binding T cells and metabolic inhibitor treatments. Murine $\mathrm{CD} 4^{+}$splenocytes were isolated from C57BL/6 mice by anti-murine CD4 L3T4 magnetic bead technology (Miltenyi Biotec Inc., Auburn, California, USA) according to the manufacturer's protocol. CD4 $4^{+}$splenocytes (99\% purity as determined by flow cytometry) were plated at $2 \times 10^{6}$ cells $/ \mathrm{ml} /$ well on 24-well plates coated with anti-murine CD3 and anti-murine CD28 (each at $1 \mu \mathrm{g} /$ well; BD Biosciences) for 48 hours in the presence or absence of murine IL-12 $(10 \mathrm{ng} / \mathrm{ml}$; BioSource International Inc., Camarillo, California, USA) and anti-murine IL-4 mAb $11 \mathrm{~B} 11(10 \mu \mathrm{g} / \mathrm{ml} ; \mathrm{BD}$ Biosciences). Culturing of murine Th cells in the presence of murine IL-12 and antimurine IL-4 produces selectin-binding Th1 cells by upregulating FucTVII $(24,25)$ and core 2 enzyme (14-16), both critical for selectin ligand synthesis (i.e., decoration of PSGL-1; refs. 1, 2, 17), and prevents the production of non-selectin-binding Th2 cells (14-16, 24, 25). Th1 cells were also generated from FucTVII-/mice and served as negative selectin-binding controls $(8-10)$. Cells were harvested and replated at $2 \times 10^{6}$ cells/ml on non-Ab-coated plastic with murine IL-2 (20 $\mathrm{ng} / \mathrm{ml}$; BioSource International Inc.) in the presence or absence of murine IL-12 $(10 \mathrm{ng} / \mathrm{ml})$ and anti-murine IL-4 mAb 11B11 $(10 \mu \mathrm{g} / \mathrm{ml})$ for 48 hours. After repeating this step two more times, cells were harvested on day 8 for functional selectin-binding analysis, and using flow cytometry, cell activation was confirmed by determination of the expression of an activation-dependent glycoform of CD43 with anti-murine CD43 mAb $1 \mathrm{~B} 11$.

For treatment with metabolic inhibitors of glycosylation, cells were replated on day 6.5 for 30 hours with $0.05 \mathrm{mM}$ 4-F-GlcNAc (a novel inhibitor of poly- $N$ acetyllactosamine synthesis) (18), $0.23 \mathrm{mM}$ swainsonine (a complex-type $N$-glycan inhibitor; Sigma Chemical Co.), or $1 \mathrm{mM}$ GlcNAc (a negative molecular sugar 
control; Sigma Chemical Co.). Before metabolic inhibitors were added to cultures producing selectin ligands, cells were first treated with Vibrio cholerae neuraminidase $\left(0.1 \mathrm{U} / \mathrm{ml}\right.$ for 1 hour at $\left.37^{\circ} \mathrm{C}\right)$ to remove all cell surface terminal sialic acid residues and $\mathrm{E}$ - and Pselectin ligand activity. Since selectin ligands are dependent on terminal sialic acid ( $\alpha 2,3-N$-acetylneuraminic acid) for activity, this approach allowed for analysis of de novo-synthesized selectin ligands in the presence of glycosylation inhibitors. The growth rates of activated murine $\mathrm{T}$ cells were identical to those of activated human $\mathrm{CLA}^{+} \mathrm{T}$ cell cultures ( 18 hours), which were treated with glycosylation inhibitors as previously described (18), and therefore these activated murine $T$ cells were exposed to similar non-growthinhibitory, selectin-modifying concentrations of glycosylation inhibitors.

Stamper-Woodruff assays. For analysis of lymphocyte adherence to skin-draining LN high endothelial venules (HEVs), shear-dependent Stamper-Woodruff assays were performed as previously described (26). Briefly, superficial inguinal LNs in mice from CHS experiments were resected, snap-frozen in liquid nitrogen, sectioned $(8 \mu \mathrm{m})$, and placed on glass slides for glutaraldehyde fixation (3\% in PBS) and lysine blocking $\left(0.2 \mathrm{M}\right.$ in $\left.\mathrm{dH}_{2} \mathrm{O}\right)$. Human peripheral blood lymphocytes, isolated from citrated-whole blood by Histopaque-1077 (Sigma Chemical Co.) density-gradient centrifugation as previously described (27), were overlaid onto fixed LN sections $\left(10^{7}\right.$ per milliliter RPMI-1640 without $\mathrm{Na}$ bicarbonate/5\% FBS) and incubated on an orbital shaker at $80 \mathrm{rpm}$ for 30 minutes at $4^{\circ} \mathrm{C}$. Lymphocyte adherence to LN HEVs was examined under light microscopy at $\times 100 \mathrm{mag}$ nification, and representative photomicrographs were taken for analysis of lymphocyte-binding specificity to HEVs (a minimum of three slides per experiment, and three separate experiments). To verify the dependence for lymphocyte L-selectin and HEV L-selectin ligand activity, lymphocytes were pretreated with functional blocking anti-human L-selectin mAb DREG-56 $(10 \mu \mathrm{g} / \mathrm{ml})$, or fixed $\mathrm{LN}$ sections were pretreated with $V$. cholerae neuraminidase $(0.1 \mathrm{U} / \mathrm{ml}$ RPMI-1640 without Na bicarbonate/2\% FBS for 30 minutes at $37^{\circ} \mathrm{C}$ ).

Parallel-plate flow chamber analysis. Tethering and rolling of Th cells on recombinant human E-selectin-Ig and P-selectin-Ig chimeras (provided by Robert Fuhlbrigge, Harvard Medical School) were analyzed in the parallelplate flow chamber under physiological shear stress conditions (18). To prepare E- and P-selectin-Ig chimera spots, protein $\mathrm{A}\left(300 \mu \mathrm{g}\right.$ per15 $\left.\mu \mathrm{l} 0.1 \mathrm{M} \mathrm{NaHCO}_{3}\right)$ was adsorbed to Ten-twenty-nine Petri dishes (Becton-Dickinson Labware, Franklin Lakes, New Jersey, USA) for 2 hours at $37^{\circ} \mathrm{C}$. HSA $(2 \mu \mathrm{g} / \mathrm{ml}$ PBS$)$ was then added for 2 hours at $37^{\circ} \mathrm{C}$ to block nonspecific binding sites. E-selectin-Ig (50 ng/50 $\mu \mathrm{l}$ PBS) or P-selectin-Ig (50 $\mathrm{ng} / 50 \mu \mathrm{lBS}$ ) solution was pipetted directly over the pre-existing protein A spots for 18 hours at $4^{\circ} \mathrm{C}$.
Murine Th1/Th0 cells treated with $V$. cholerae neuraminidase and with 4-F-GlcNAc, swainsonine, PBS (diluent control), or GlcNAc (molecular control) as described above were washed twice in HBSS, suspended at $2 \times 10^{6}$ per milliliter in HBSS $/ 10 \mathrm{mM}$ HEPES $/ 2 \mathrm{mM}$ $\mathrm{CaCl}_{2}\left(\mathrm{H} / \mathrm{H} / \mathrm{Ca}^{++}\right)$, and infused into the chamber over selectin chimeras. Cell tethering was permitted at 0.6 dynes $/ \mathrm{cm}^{2}$ for 1 minute, and then stepwise increments in shear stress every 15 seconds were employed to a final shear stress level of 60 dynes $/ \mathrm{cm}^{2}$. Assessments of cell rolling were made at 1.5 dynes $/ \mathrm{cm}^{2}$ from the midpoint of the chamber viewing field (four fields per selectin spot, three different experiments) at $\times 200$ magnification. All experiments were observed in real time and videotaped for off-line analysis. Negative-control experiments, performed in parallel, examined cell binding in $\mathrm{H} / \mathrm{H}$ adhesion assay medium containing $5 \mathrm{mM}$ EDTA to chelate the $\mathrm{Ca}^{++}$required for selectin binding and to assay cell binding to human IgG isotype control.

Langerhans cell migration assay. For analysis of antigen processing and presentation to skin-draining LNs, right ears of mice were painted with $25 \mu \mathrm{l}$ of $0.5 \%$ FITC, a contact-sensitizing agent dissolved in acetone/dibutyl phthalate vehicle $(1: 1 \mathrm{vol} / \mathrm{vol})$, while left ears were painted with $25 \mu \mathrm{l}$ of vehicle alone. After 24 hours, regional auricular or cervical LNs draining right or left ears, respectively, were isolated, and single-cell suspensions were prepared. Ipsilateral LNs from three mice of the same experimental group were combined for analysis of DCs presenting FITC or Langerhans cells (LCs) originating from the epidermis. To enrich for DCs, cell suspensions were subjected to OptiPrep (Accurate Chemical \& Scientific Corp., Westbury, New York, USA) discontinuous-gradient centrifugation according to the manufacturer's protocol. DC-enriched cell preparations were incubated with phycoerythrin-labeled (PE-labeled) anti-murine CD11c (an integrin $\alpha_{x}$ chain and murine DC marker) for 30 minutes on ice, washed three times with $\mathrm{PBS} / 2 \% \mathrm{FBS}$, and suspended in PBS for flow cytometric analysis. Cell staining with isotype-matched control PE-hamster IgG1 $\lambda$ was also performed to control for PE-anti-CD11c-binding specificity. Furthermore, for double-staining analysis of $\mathrm{CD} 11 \mathrm{c}^{+} \mathrm{DCs}$ presenting FITC, FITC- and PE-intensity compensation settings were preadjusted to positive staining of murine lymphocytes with PE-labeled rat IgG2b $\kappa$ anti-murine CD4 (clone L3T4) or FITC-labeled rat IgG1 $\kappa$ anti-murine CD8b.2 (Ly-3.2; clone 53-5.8). Cells staining positive with anti-murine $\mathrm{CD} 11 \mathrm{cmAb}$ were gated and analyzed for FITC expression.

To study the effects of 4-F-GlcNAc on FITC presentation to skin-draining LNs, mice were treated intraperitoneally daily with 50,100 , or $250 \mathrm{mg} / \mathrm{kg} 4-\mathrm{F}-\mathrm{GlcNAc}$ (in $0.9 \%$ saline) for 4 days (days -3 to 0 ) prior to sensitization with FITC. There were duplicate groups per dose and three mice per group from three experiments.

Murine model of allergic CHS. To induce CHS reactions, mice were sensitized on the abdomen on days 0 and 1 with $25 \mu \mathrm{l}$ of $0.5 \%$ 2,4-dinitrofluorobenzene (DNFB) in 
a 4:1 solution of acetone/olive oil (vehicle). To demonstrate the dependence of $\mathrm{T}$ cell antigen recognition and activation for elicitation of allergic CHS responses, negative controls were also performed in which mice were sensitized with hapten vehicle alone. Mice were then treated from day 1 to day 6 with drug vehicle $(0.9 \%$ saline); 50,100 , or $250 \mathrm{mg} / \mathrm{kg} 4-\mathrm{F}-\mathrm{GlcNAc} ; 250 \mathrm{mg} / \mathrm{kg}$ GlcNAc (negative molecular sugar control); or $5 \mathrm{mg} / \mathrm{kg}$ swainsonine. Previous studies evaluating in vivo antitumor and antimetastatic effects of fluorinated hexosamine analogs indicated that the dose that limited toxicity of 4-F-GlcNAc was $250 \mathrm{mg} / \mathrm{kg}$ for 6 days and that intraperitoneal administration of these sugar analogs was an efficacious mode of delivery (28-30). Thus, we incorporated a maximal dose of $250 \mathrm{mg} / \mathrm{kg}$ as well as doses of 100 and $50 \mathrm{mg} / \mathrm{kg}$ to assess both toxicity and efficacy. Furthermore, a swainsonine dose of 5 $\mathrm{mg} / \mathrm{kg}$ was selected based on in vivo antitumor-efficacy experiments that showed that swainsonine reduced complex-type $\mathrm{N}$-glycans expressed on target tumor cells at a dose of $4 \mathrm{mg} / \mathrm{kg}$ (31) and that it might enhance CHS responses (32). Hapten-induced inflammation was then promoted on day 6 by challenging of mice with $10 \mu \mathrm{l}$ of $0.25 \%$ DNFB on both sides of the right ear, and, as a negative inflammatory control, mice also received $10 \mu \mathrm{l}$ of vehicle alone on both sides of the left ear. Ear-swelling responses were determined by calculation of the difference in ear thickness between day 7 ( 24 hours after challenge) and day 6 (before challenge). There were eight mice per group for a minimum of three experiments.

To help define the effect of 4-F-GlcNAc on either the afferent or the efferent immunological phase of CHS, we elicited CHS in mice after a 12 -day period and treated mice with 4-F-GlcNAc or diluent control either from day 1 to day 6 or from day 6 to day 11 . Similar to the 7 - day protocol described above, mice were sensitized with $0.5 \%$ DNFB on days 0 and 1 and challenged on day 11 , and ear-swelling responses were determined by calculation of the difference in ear thickness between day 12 (before challenge) and day 13.

SDS-PAGE and Western blotting. For analysis of E-selectin ligand and PSGL-1 levels on lymphocytes from LNs draining DNFB-sensitized skin, we isolated inguinal LNs from mice in CHS experiments (on day 7 after DNFB sensitization) and prepared lysates for Western blot analysis. Lymphocytes were released from LNs by mechanical disruption in ice-cold PBS, which was passed through a $70-\mu \mathrm{m}$ cell strainer and subjected to density-gradient centrifugation. Lymphocytes were then placed in lysis buffer containing a protease inhibitor cocktail and 2\% NP-40 (18), incubated for 18 hours on ice, and centrifuged at $9,880 \mathrm{~g}$ for $30 \mathrm{~min}-$ utes. Clarified lysates were quantified using the Bradford reagent method (Sigma Chemical Co.). Lysates (40 $\mu \mathrm{g} /$ lane) were resolved on reducing 4-20\% SDSPAGE gradient gels, transferred to PVDF membrane and blocked for 1 hour in FBS at room temperature. Blots were stained with recombinant mouse E-selectin-human Ig chimera (R\&D Systems Inc., Minneapolis, Minnesota, USA) at $1 \mu \mathrm{g} / \mathrm{ml}$ PBS containing $2 \mathrm{mM} \mathrm{CaCl}{ }_{2}$ or with rabbit anti-sera against mouse PSGL-1 (generously provided by Bruce Furie, Beth Israel Deaconess Medical Center, Harvard Medical School) for 1 hour at room temperature. After washing three times in PBS $/ 0.1 \%$ Tween-20, blots were incubated with alkaline phosphatase-conjugated (AP-conjugated) goat anti-human IgG $(1: 2,000)$ or APconjugated goat anti-rabbit IgG $(1: 2,000)$ for 30 minutes at room temperature, washed three times with PBS/0.1\% Tween-20, and developed with Western Blue
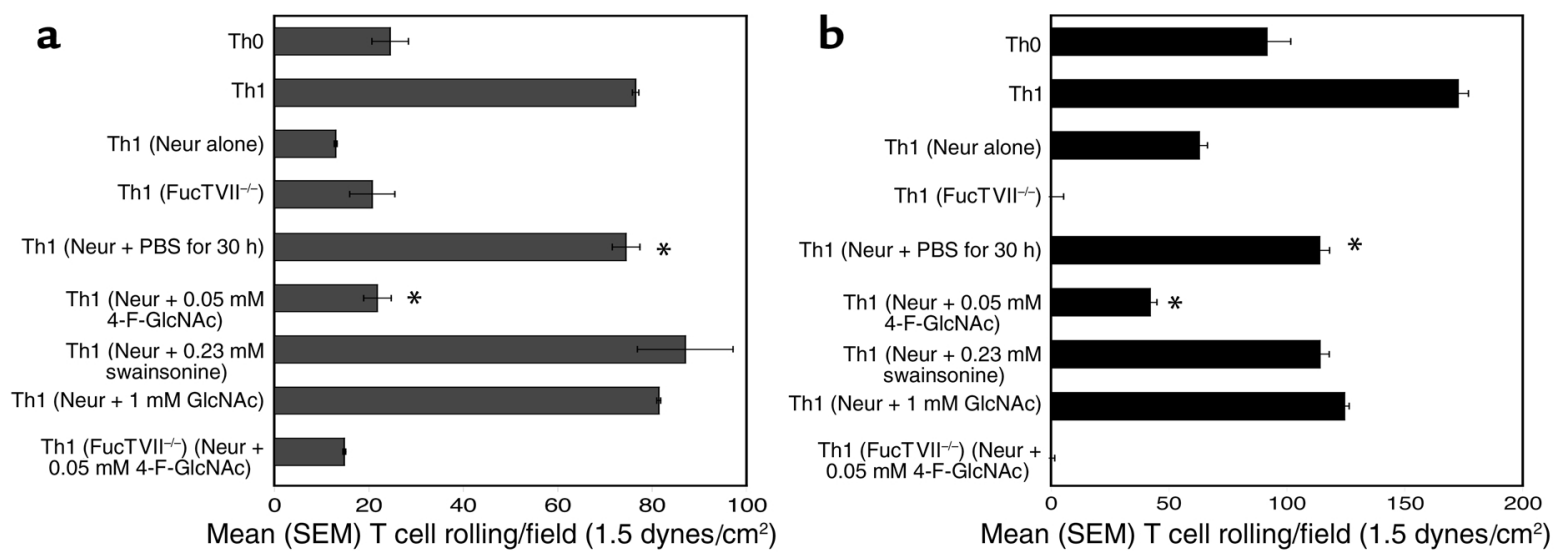

\section{Figure 1}

Parallel-plate flow chamber analysis of E- and P-selectin binding of murine Th cells following 4-F-GlcNAc treatment. Murine Th1 cells were generated from spleens of C57BL/ 6 wild-type and FucTVII-deficient mice. To assess the effects of 4-F-GlcNAc on the de novo synthesis of selectin ligands, Th1 cell cultures were first treated with neuraminidase $\left(0.1 \mathrm{U} / \mathrm{ml}\right.$ for 1 hour at $\left.37^{\circ} \mathrm{C}\right)$ and then regrown for 30 hours in fresh medium containing PBS (diluent), $0.05 \mathrm{mM}$ 4-F-GlcNAc, $0.23 \mathrm{mM}$ swainsonine, or $1 \mathrm{mM} \mathrm{GlcNAc}$ (negative control). Cells were harvested, suspended in HBSS with $2 \mathrm{mM} \mathrm{CaCl}_{2}$ and $10 \mathrm{mM} \mathrm{HEPES}$, and perfused over human recombinant E-selectin-Ig chimera (a) or P-selectin-lg chimera (b) in the parallel-plate flow chamber. Assessments of cell rolling were made at 1.5 dynes $/ \mathrm{cm}^{2}$ from the midpoint of the chamber viewing field (mean \pm SEM from four fields per selectin spot and three different experiments). Rolling Th1 cells on E- or P-selectin-lg were inhibitable with 0.5 mM EDTA, and rolling adhesions on human IgG-coated plastic were absent. ${ }^{*} P<0.001$, Student's paired $t$ test. Neur, neuraminidase. 


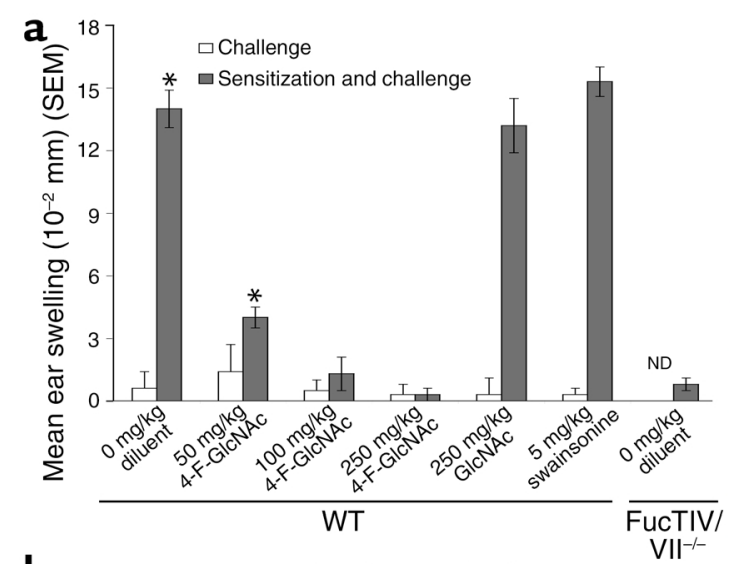

b

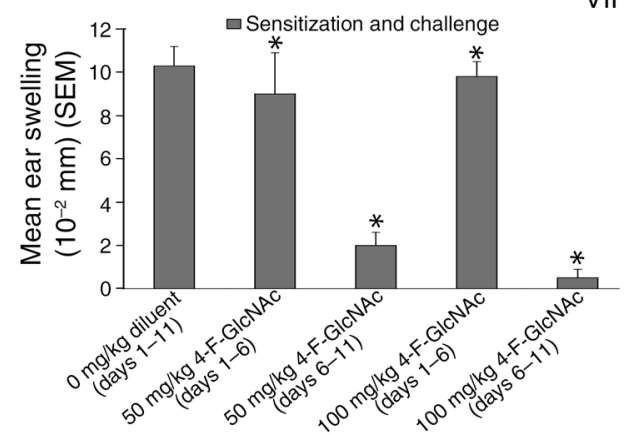

C

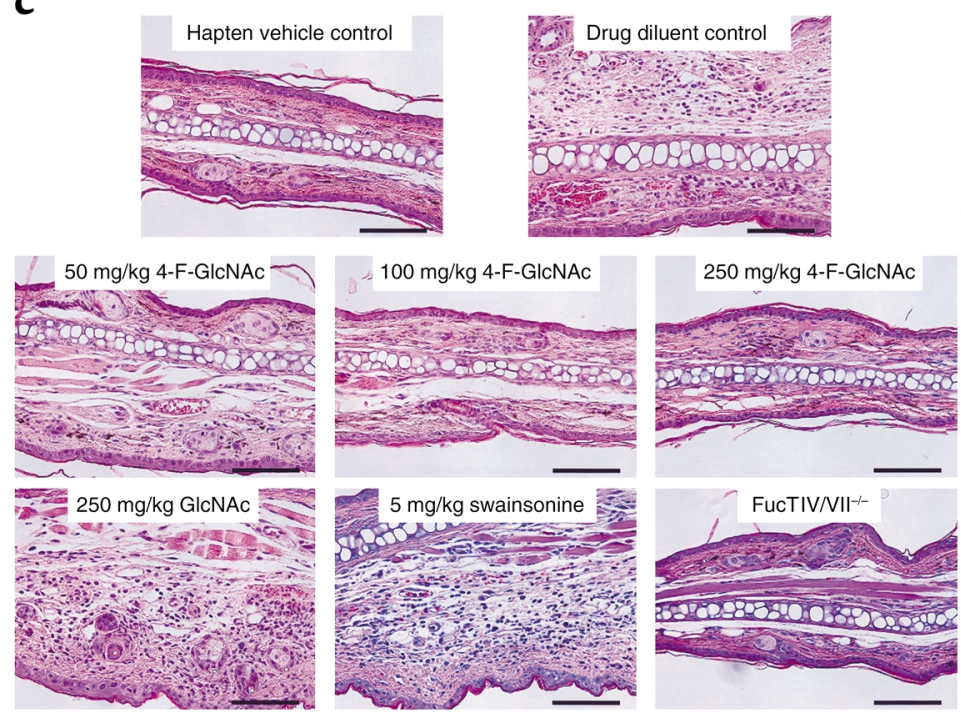

Figure 2

Allergic CHS in mice treated with 4-F-GlcNAc. (a) Wild-type mice were sensitized on the abdomen with $0.5 \%$ DNFB in vehicle (acetone/olive oil, 4:1) on days 0 and 1 . Mice were given $0.9 \%$ saline (diluent), 50, 100, or $250 \mathrm{mg} / \mathrm{kg} 4-\mathrm{F}-\mathrm{GlcNAc}, 5 \mathrm{mg} / \mathrm{kg}$ swainsonine, or $250 \mathrm{mg} / \mathrm{kg}$ GlcNAc (negative drug control) intraperitoneally daily from day 1 to day 6 . FucTIV/VII-null mice were also sensitized with $0.5 \%$ DNFB and treated with diluent control. Mice were then challenged on the right ear on day 6 with $0.25 \%$ DNFB and on the left ear with vehicle alone. After 24 hours, ear swelling was determined by measurement of ear thickness, which was subtracted from base-line ear-thickness measurements. ${ }^{*} P<0.0002$, Student's paired $t$ test. ND, not determined. (b) Wild-type mice were sensitized on the abdomen with $0.5 \%$ DNFB on days 0 and 1. Mice were given diluent control or 50 or $100 \mathrm{mg} / \mathrm{kg} 4-\mathrm{F}-\mathrm{GlcNAc}$ intraperitoneally daily either from day 1 to day 6 or from day 6 to day 11 . Mice were then challenged on the right ear on day 11 with $0.25 \%$ DNFB and on the left ear with vehicle alone. After 24 hours, ear swelling was determined. ${ }^{*} P<0.007$, Student's paired $t$ test. Data in $\mathbf{a}$ and $\mathbf{b}$ represent mean ear swelling \pm SEM from eight mice per group and three experiments. (c) Representative photomicrographs of H\&E-stained sections from ears of mice sensitized and challenged with $0.5 \%$ DNFB illustrate differences in ear thickness between mice treated with diluent control and with 4-F-GlcNAc. $\times 200$ magnification. Bar: $100 \mu \mathrm{m}$.

(Promega Corp., Madison, Wisconsin, USA). These studies were preformed in triplicate. Negative-control blots were prepared in parallel wherein blots were stained with AP-conjugated Ab's alone, and mouse E-selectin-Ig chimera staining was executed in the presence of $5 \mathrm{mM}$ EDTA.

\section{Results}

Effects of 4-F-GlcNAc treatment on murine T cell binding to E-selectin and P-selectin. Before evaluating in vivo efficacy of 4-F-GlcNAc, we first investigated the potential of 4-F-GlcNAc treatment to interfere with the biosynthesis of carbohydrate structures critical for effector $\mathrm{T}$ cell binding to E-selectin and P-selectin. As an in vitro model of $\mathrm{T}$ cells expressing selectin ligand Th1 cells were generated and analyzed for selectin ligand activity after 4-F-GlcNAc treatment (1, 2, 5, 11-14). Th cell cultures were first digested with neuraminidase to eliminate all selectin ligand activity and then incubated for 30 hours with 4-F-GlcNAc, swainsonine, or GlcNAc (negative molecular sugar control) to analyze de novo-synthesized carbohydrate selectinbinding determinants. To confirm $\mathrm{T}$ cell activation and O-glycosylation (14-16), flow cytometric analysis of an activation-dependent O-glycan on CD43 was performed. It revealed that 4-F-GlcNAc did not markedly affect activated CD43 glycoform levels (100\% positive; mean channel fluorescence [MCF] of $1,400)$ when compared with diluent control or other treatments (99\% positive; MCF of 1,900). 4-F-GlcNAc was also incubated during the initial $\mathrm{T}$ cell plating on plastic coated with anti-CD3 mAb and, when compared with diluent control did not cause any difference in $\mathrm{T}$ cell proliferation rate or level of activationdependent CD43 (data not shown).

Using the parallel-plate flow chamber, we found that neuraminidase treatment alone decreased E- and P-selectin ligand activity to base-line levels expressed by Th0 or FucTVII ${ }^{-/-}$Th1 cells (Figure 1 , a and b). Compared with Th1 cells recovered in PBS, GlcNAc, or swainsonine, Th1 cells recovered in 4-F-GlcNAc showed significantly inhibited re-expression of E-and 
P-selectin ligand activities $(P<0.001$, Student's paired $t$ test) (Figure 1, a and b) but did not affect PSGL-1 polypeptide and CD18 expression as determined by flow cytometry (MCF of 1,184 and 440, respectively, compared with 1,168 and 408 in PBS control). Collectively, these data reaffirm the critical requirement for $\alpha 1,3$-fucosylation and poly- $N$-acetyllactosamine decoration of PSGL-1 core $2 \mathrm{O}$-glycans for T cell binding to $\mathrm{E}$ - and $\mathrm{P}$-selectin and provide therapeutic rationale for use of 4-F-GlcNAc in preventing $\mathrm{T}$ cell migration to inflamed skin.

Effects of 4-F-GlcNAc treatment on allergic CHS. To investigate in vivo efficacy of 4-F-GlcNAc in a model of allergic CHS, we used a standard 7-day protocol, in which DNFB antigen sensitization was performed on days 1 and 2, 4-F-GlcNAc intraperitoneal treatment on days 1-6, DNFB challenge on day 6 , and assessment of inflammatory response on day 7 . Using this sensitization/challenge schedule and DNFB hapten in C57BL/6 mice, recruitment of effector T cells into CHS-reactive sites is dependent on dermal endothelial E- and P-selectins and an $\alpha 1,3$-fucosyltransferase-decorated PSGL-1 molecule (1-13) and is therefore a pertinent model for assessing anti-inflammatory activity of 4-F-GlcNAc. Since $250 \mathrm{mg} / \mathrm{kg} 4-\mathrm{F}-$ GlcNAc has been shown to be dose limiting in early studies of antitumor efficacy $(28-30)$, we treated mice at the upper limit of $250 \mathrm{mg} / \mathrm{kg} 4-\mathrm{F}-\mathrm{GlcNAc}$ and at lower doses of 100 and $50 \mathrm{mg} / \mathrm{kg} 4-\mathrm{F}-\mathrm{GlcNAc}$ to examine both toxicity and efficacy. As positive inflammatory controls, mice were also treated with diluent control ( $0.9 \%$ saline), GlcNAc (molecular control), or swainsonine at a dose previously shown to modify complex-type $N$-glycans expressed on target tumor cells (31). We speculated that reductions in $\mathrm{T}$ cell complex-type $\mathrm{N}$-glycans, which are negative regulators of $\mathrm{T}$ cell activation, could possibly enhance CHS responses (32). In mice receiving both sensitizing and challenging doses of DNFB, we found that both 100 and $250 \mathrm{mg} / \mathrm{kg} \mathrm{4-F-Glc-}$ NAc completely abrogated CHS reactions, as indicated by a lack of ear swelling (Figure 2a). While some toxicity was observed in mice dosed at $250 \mathrm{mg} / \mathrm{kg}$, as evidenced by a reduction in body weight $(5 \%)$, the $100-\mathrm{mg} / \mathrm{kg}$ dose was well tolerated. Even a fivefold lower dose of $50 \mathrm{mg} / \mathrm{kg}$ 4-F-GlcNAc caused a statistically significant diminution in the inflammation $(P<0.0002$, Student's paired $t$ test), while negative drug controls, diluent control, and GlcNAc had no antiinflammatory effect (Figure 2a). Furthermore, CHS reactions in mice receiving only DNFB challenge and in FucTIV/VII ${ }^{-/}$mice

Table 1 receiving both DNFB sensitizing and challenging doses were minimal, while swainsonine-treated mice showed normal CHS responses (Figure 2a).

Effects of 4-F-GlcNAc on the afferent and/or efferent phases of allergic CHS. To help determine whether 4-F-GlcNAc affected the afferent and/or effector phases of allergic CHS, we performed CHS experiments that entailed a longer period between DNFB sensitization and challenge. DNFB sensitization/challenge doses and the 24-hour elicitation period were unchanged, though 4-F-GlcNAc treatment was divided into two treatment periods, early (days 1-6) and late (days 6-11). Prior studies show that induction of E- and Pselectin ligand expression on effector $\mathrm{T}$ cells after DNFB sensitization is maximal after about 5 days, indicating that DNFB presentation and $\mathrm{T}$ cell activation most likely occur within the first 4 days after sensitization (33). Since our initial analysis of 4-F-GlcNAc efficacy consisted of treatment during the critical first 4 days, we treated mice from day 6 to day 11 to examine the effect of 4-F-GlcNAc on the efferent phase of CHS. We found that ear swelling measured on day 12 was robust in mice treated from day 1 to day 11 with diluent control and from day 1 to day 6 with either 50 or $100 \mathrm{mg} / \mathrm{kg} 4-\mathrm{F}-\mathrm{GlcNAc}$ (Figure $2 \mathrm{~b}$ ). In contrast, mice treated from day 6 to day 11 with 50 or 100 $\mathrm{mg} / \mathrm{kg}$ 4-F-GlcNAc showed diminished ear swelling responses $(P<0.007)$ (Figure $2 \mathrm{~b})$.

To analyze mononuclear cell infiltrates in ear skin from control and 4-F-GlcNAc-treated mice, we stained ear sections with $\mathrm{H} \& \mathrm{E}$ and performed histological analysis by light microscopy. As depicted in Figure $2 c$, inflammatory mononuclear infiltrate was minimal in ear skin challenged with hapten vehicle alone and in ear skin from FucTIV/VII-null mice sensitized and challenged with DNFB. In addition, a dose-dependent response due to 4-F-GlcNAc treat-

Effects of 4-F-GlcNAc treatment on the level ofT lymphocytic infiltrate in inflamed ear skin from mice in allergic $\mathrm{CHS}$ experiments

Antigen sensitization/challenge

$0.5 \% \mathrm{DNFB} /$ hapten vehicle

$0.5 \% \mathrm{DNFB} / 0.25 \% \mathrm{DNFB}$

$0.5 \% \mathrm{DNFB} / 0.25 \% \mathrm{DNFB}$

$0.5 \% \mathrm{DNFB} / 0.25 \% \mathrm{DNFB}$

$0.5 \%$ DNFB $/ 0.25 \%$ DNFB

$0.5 \% \mathrm{DNFB} / 0.25 \% \mathrm{DNFB}$

$0.5 \%$ DNFB $/ 0.25 \%$ DNFB

$0.5 \% \mathrm{DNFB} / 0.25 \% \mathrm{DNFB}$

Drug treatment ${ }^{\mathrm{A}}$
$0.9 \%$ Saline
$0.9 \%$ Saline
$50 \mathrm{mg} / \mathrm{kg} 4-\mathrm{F}-\mathrm{GlcNAc}$
$100 \mathrm{mg} / \mathrm{kg} 4-\mathrm{F}-\mathrm{GlcNAc}$
$250 \mathrm{mg} / \mathrm{kg} 4-\mathrm{F}-\mathrm{GlcNAc}$
$250 \mathrm{mg} / \mathrm{kg} \mathrm{GlcNAc}$
$5 \mathrm{mg} / \mathrm{kg}$ swainsonine
$0.9 \%$ Saline (FucTIV/VII-/- mice)

$0.9 \%$ Saline (FucTIV/VII--- mice)

Mean $( \pm \mathrm{SD}) \mathrm{CD}^{+}$cells $^{\mathrm{B}}$
$2.8 \pm 1.7^{\mathrm{C}}$
$24.5 \pm 5.2$
$10.0 \pm 3.0^{\mathrm{C}}$
$2.2 \pm 1.2^{\mathrm{C}}$
$2.2 \pm 1.2^{\mathrm{C}}$
$21.5 \pm 3.1$
$29.5 \pm 6.9$
$3.8 \pm 2.6^{\mathrm{C}}$

Mice were treated daily on days 1-6 intraperitoneally with 50,100 , or $250 \mathrm{mg} / \mathrm{kg}$ 4-F-GlcNAc, 250 $\mathrm{mg} / \mathrm{kg} \mathrm{GlcNAc}$ (molecular control), or $5 \mathrm{mg} / \mathrm{kg}$ swainsonine solubilized in $0.9 \%$ saline diluent. ${ }^{\text {BThe }}$ number of cells stained red with rabbit anti-CD3 polyclonal Ab from eight independent fields at $\times 200$ magnification in sections from the thickest regions of inflamed ear skin, from two independent experiments. Performance of immunohistochemical staining on inflamed ear skin with HRP-conjugated swine anti-rabbit Ab and Vector Nova Red substrate alone showed no cell staining and served as negative control. ' 'Statistically significant difference in the level of $\mathrm{CD}^{+}$cells in ear skin between mice challenged with $0.5 \%$ DNFB and treated with $0.9 \%$ saline and mice challenged with $0.5 \%$ DNFB and treated with 50,100 , or $250 \mathrm{mg} / \mathrm{kg} 4-\mathrm{F}-\mathrm{GlcNAc}$ or FucTIV $/ \mathrm{VII}^{-/-}$mice challenged with $0.5 \%$ DNFB and treated with $0.9 \%$ saline $(P<0.003$, Student's paired $t$ test). 


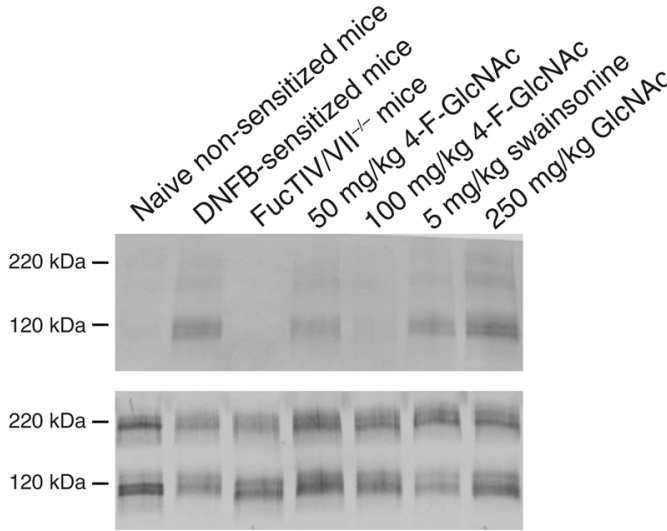

\section{Figure 3}

Effects of 4-F-GlcNAc on effector lymphocyte E-selectin ligand and PSGL-1 expression. Lymphocytic lysates were prepared from inguinal LNs draining DNFB-sensitized skin after day 7 of DNFB sensitization. Lysates ( $40 \mu \mathrm{g} /$ lane) were separated on reducing 4-20\% SDS-PAGE gradient gels, transferred to PVDF membrane, and blotted with mouse E-selectin- $\mathrm{Ig}(1 \mu \mathrm{g} / \mathrm{ml})(\mathbf{a})$ or rabbit anti-sera against mouse PSGL-1 $(0.5 \mu \mathrm{g} / \mathrm{ml})(\mathbf{b})$ and relevant AP-conjugated secondary Ab's $(1: 2,000)$ and AP substrate solution. Negative control blots, E-selectin-Ig staining in the presence in $5 \mathrm{mM}$ EDTA or AP-conjugated secondary Ab's alone, did not show any signal. Please note the induction of lymphocyte E-selectin ligand principally by the 120 - and $220-\mathrm{kDa}$ isoforms of PSGL-1, as well as by a $190-\mathrm{kDa}$ glycoprotein from skin-draining LNs of DNFB-sensitized mice (a). Also, though PSGL-1 levels were relatively unchanged (b), lymphocyte E-selectin ligand induction from skin-draining LNs of DNFB-sensitized FucTIV/VII--- mice or of DNFBsensitized mice treated with $100 \mathrm{mg} / \mathrm{kg}$ 4-F-GlcNAc was absent (a). ment was evident and the level of inflammatory mononuclear cell infiltrate was considerably lowered in those skin tissues (Figure 2c).

Immunohistochemical studies examining the level of effector lymphocytic infiltrate in inflamed ear skin detected $\mathrm{CD}^{+} \mathrm{T}$ cells, which include $\mathrm{CD} 4^{+}, \mathrm{CD}^{+}$, and $\gamma \delta \mathrm{T}$ cell subsets, in inflamed ear skin from diluent control- and GlcNAc-treated mice, while slightly higher levels of $\mathrm{CD}^{+} \mathrm{T}$ cells were found in inflamed ear skin from swainsonine-treated mice (Table 1). On the other hand, all doses of 4-F-GlcNAc caused significant inhibition of $\mathrm{CD}^{+} \mathrm{T}$ cell infiltrate in DNFB-challenged ear skin $(P<0.003)$. Moreover, mice challenged with hapten vehicle alone and FucTIV $/ \mathrm{VII}^{-/-}$mice sensitized and challenged with DNFB showed a low level of $\mathrm{CD}^{+} \mathrm{T}$ cell infiltrate (Table 1 ).

To analyze the effects of 4-F-GlcNAc on the capacity of effector lymphocytes to synthesize E-selectin ligand, inguinal LNs draining DNFB-sensitized skin from mice in CHS experiments (day 7 after DNFB sensitization) were isolated, and lymphocytic lysates were prepared. Lymphocytic lysates (of equal protein concentration) were resolved by SDS-PAGE and blotted with mouse E-selectin-Ig chimera. As illustrated in Figure 3a, lymphocytes from naive non-DNFB-sensitized mice expressed minimal E-selectin ligand, while E-selectin ligand expression (principally a $120-\mathrm{kDa}$ glycoprotein) was upregulated on lymphocytes from LNs draining DNFB-sensitized skin. In FucTIV/VII ${ }^{-/}$mice, E-selectin ligand expression on lymphocytes in LNs draining DNFB-sensitized skin was absent, indicating the importance of $\alpha 1,3$-fucosylation in generating a skin-homing phenotype or E-selectin ligand (Figure 3a). Lymphocyte E-selectin ligand synthesis was inhibited in a dose-dependent manner by 4-F-GlcNAc treatment and was absent in mice treated with $100 \mathrm{mg} / \mathrm{kg}$ 4-F-GlcNAc, whereas swainsonine and GlcNAc did not lower ligand expression (Figure 3a). To show that the $120-\mathrm{kDa}$ glycoprotein was the monomer form of PSGL-1, Western blots of lymphocytic lysates were analyzed for PSGL-1 expression. As shown in Figure 3b, PSGL-1 levels were similar among all groups analyzed for E-selectin ligand expression, and the monomer form of PSGL-1 (120 kDa) was most likely the $120-\mathrm{kDa}$ glycoprotein carrier of lymphocyte E-selectin ligand.

To further support the observed inhibitory effects on the effector phase of allergic CHS, we examined the effects of 4-F-GlcNAc on antigen processing in the

\section{Figure 4}

Effects of 4-F-GlcNAc on antigen presentation in regional skin-draining LNs. Following a 4-day intraperitoneal pretreatment with diluent control or with 50,100 , or $250 \mathrm{mg} 4-\mathrm{F}-\mathrm{GlcNAc}$, mice were sensitized on the right ear with $0.5 \%$ FITC (acetone/dibutyl phthalate, $1: 1$ ) and on the left ear with vehicle alone. After 30 hours, DC-enriched cells from ipsilateral cervical/auricular nodes from three mice were stained with PE-anti-CD11c mAb for flow cytometry. Representative histograms of green fluorescence (FITC) of CD11 $c^{+}$cells from DCenriched cells prepared from skin-draining LNs of the left side or from contralateral skin-draining LNs of the right side illustrate the increased level of FITC-expressing DCs from LNs draining right FITC-sensitized ears. Data show a lack of dose response due to 4-F-GlcNAc treatment, though a slight increase in DCs staining positive for FITC was observed in all 4-F-GlcNAc-treated mice. Percent positive FITC expression is indicated in diluent control by subtracting gates R8 from R7 (8\%); in 50 $\mathrm{mg} / \mathrm{kg}$ 4-F-GlcNAc by subtracting gates R10 from R9 (12\%); in 100 $\mathrm{mg} / \mathrm{kg}$ 4-F-GlcNAc by subtracting gates R12 from R11 (13\%); and in $250 \mathrm{mg} / \mathrm{kg}$ 4-F-GlcNAc by subtracting gates R14 from R13 (10\%). These data are representative of three independent experiments.

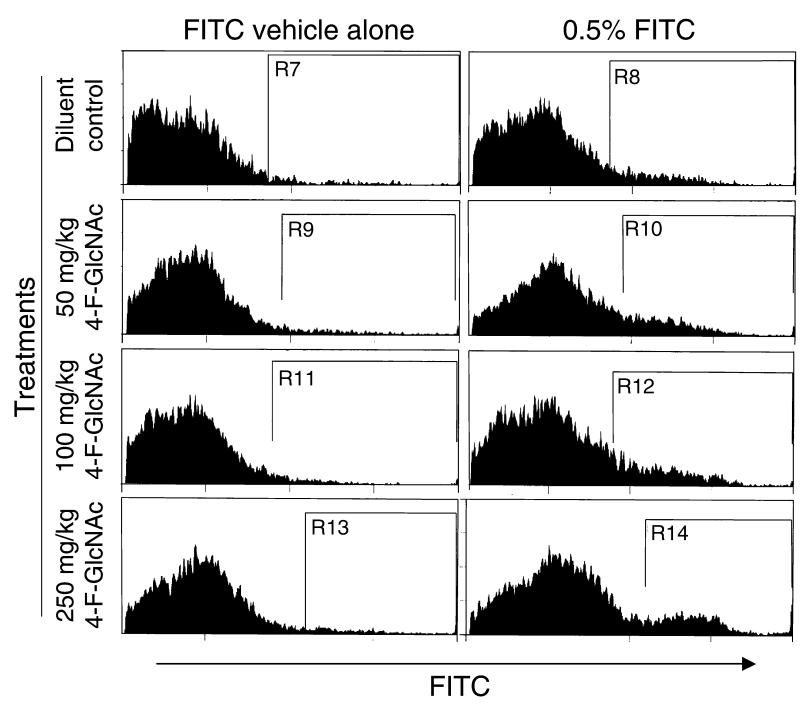


epidermis and presentation to skin-draining LNs (13). Accordingly, prior to hapten sensitization on ear skin, mice were treated intraperitoneally for 4 days with diluent control or 50, 100 , or $250 \mathrm{mg} / \mathrm{kg}$ 4-F-GlcNAc. Mice were then sensitized on the right ear with a contact-sensitizing agent, $0.5 \%$ FITC in acetone/dibutyl phthalate (1:1), or on the left ear with FITC vehicle alone to serve as the negative control. Following a 24hour incubation, cells were isolated from auricular and cervical LNs draining either right or left ears and analyzed for FITC expression by flow cytometry. Ipsilateral LN cells from three mice were combined for each experimental group. Cells were then stained with an mAb against murine CD11c, a DC surface marker. This approach allowed for the identification of DCs expressing both CD11c and FITC or antigen-presenting LCs originating from the epidermis. Though a slight increase was observed in the frequency of DCs expressing FITC in mice treated with 4-F-GlcNAc compared with saline-treated mice, these elevations were not dose dependent (Figure 4). These data suggested that 4-F-GlcNAc did not inhibit the migration of antigen-presenting LCs to skin-draining LNs, altering the afferent or sensitization phase of the CHS immunological process.

To analyze the capacity of naive $\left(\mathrm{L}-\right.$ selectin $\left.^{+}\right) \mathrm{lym}$ phocytes to migrate into skin-draining LNs, we performed Stamper-Woodruff assays on frozen sections of superficial inguinal LNs isolated from mice in CHS experiments that received 6-day intraperitoneal drug treatment. Skin-draining LN sections from FucTIV $/ \mathrm{VII}^{-}-$- mice that received 6-day intraperitoneal treatment of diluent control were also analyzed to serve as a negative lymphocyte-binding control. As shown in Figure 5, HEVs supporting lymphocyte adherence were demarcated by a red line to help illustrate observed differences in HEV lymphocyte-binding activity. We found that lymphocytes bound to LN HEVs from drug controls in an L-selectin-dependent manner and that lymphocyte binding to skindraining LN HEVs was not influenced by 6-day intraperitoneal treatments with 50 or $100 \mathrm{mg} / \mathrm{kg}$ 4-F-GlcNAc (Figure 5). 4-F-GlcNAc treatment at $250 \mathrm{mg} / \mathrm{kg}$ revealed an observable reduction in lymphocyte adherence to $\mathrm{LN}$ HEVs, as indicated by the lower frequency of HEVs supporting lymphocyte binding (Figure 5). Since lymphocyte adherence to
LN HEVs is dependent on functional expression of L-selectin ligands on LN HEVs, the absence of inhibitory lymphocyte-binding activity at 50 and $100 \mathrm{mg} / \mathrm{kg}$ 4-F-GlcNAc suggested that L-selectin ligand expression was unaffected. Thus, observed anti-inflammatory effects with 50 or $100 \mathrm{mg} / \mathrm{kg}$ 4-F-GlcNAc in CHS experiments most likely did not alter the capacity of naive lymphocytes to enter skin-draining LNs and diminish the $\mathrm{T}$ cell antigen recognition and activation phase that is critical for an allergic CHS response.

\section{Discussion}

The immunological pathways required for allergic $\mathrm{CHS}$ reactions involve (a) antigen uptake by epidermal LCs; (b) LC migration to skin-draining LNs; (c) antigen recognition by recirculating naive $\mathrm{T}$ cells, resulting in $\mathrm{T}$ cell activation and $\mathrm{E}$ - and $\mathrm{P}$-selectin ligand synthesis; and (d) effector T cell migration to skin following antigenic recall (34). Though effector inflammatory infiltrate contains a variety of leukocytes, such as DCs, granulocytes, and monocytes/macrophages $(4,5,34$, 35), E- and P-selectin-binding activity on effector $\mathrm{CD} 4^{+}$ and $\mathrm{CD}^{+} \mathrm{T}$ cell subsets is critical for the elicitation of allergic CHS $(1,2,5,7,13)$. These effector $\mathrm{T}$ cells contain glycosylation machinery necessary to generate a "skin-homing" ligand that binds endothelial E-selectin and P-selectin and that is critical for initiation of their

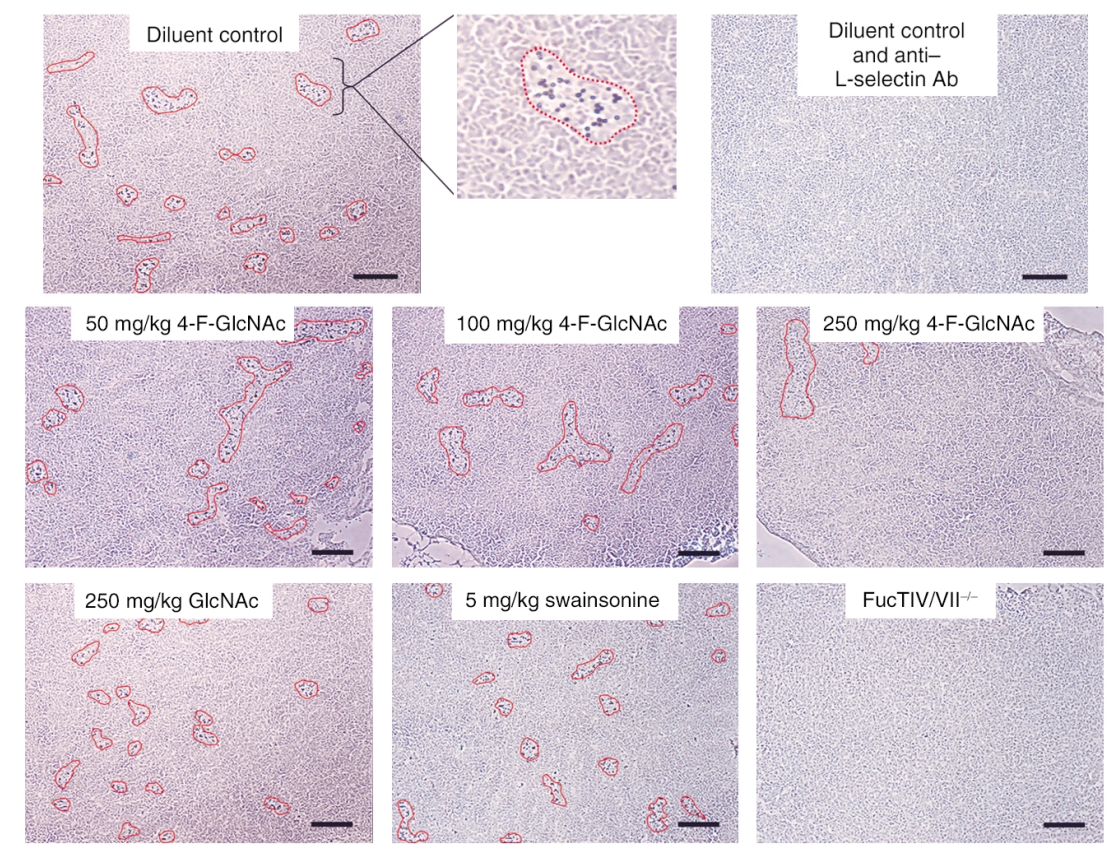

\section{Figure 5}

Effects of 4-F-GlcNAc on lymphocyte binding to skin-draining LN HEVs. To examine L-selectin ligand activity of HEVs in inguinal LNs draining antigen-sensitized skin from mice treated with $4-\mathrm{F}-\mathrm{GlcNAc}$, Stamper-Woodruff assays were performed. Lymphocyte suspensions $\left(10^{7} \mathrm{per}\right.$ milliliter) were overlaid onto glass slides containing glutaraldehyde-fixed $\mathrm{LN}$ sections $(8 \mu \mathrm{m})$ and incubated for 30 minutes at $4^{\circ} \mathrm{C}$ under a constant rotation of $80 \mathrm{rpm}$. Slides were rinsed in cold PBS and incubated in glutaraldehyde for 10 minutes. In representative photomicrographs, lymphocytes (black dots) bound in an L-selectin-dependent manner to LN HEVs (outlined in red). At least three slides per experiment were used, and three independent experiments were performed. $\times 100$ magnification. Bar: $100 \mu \mathrm{m}$. 
entry into antigenic recall sites in skin. Our previous studies with 4-F-GlcNAc, a novel metabolic inhibitor of poly- $N$-acetyllactosamine synthesis, demonstrate potent downregulation of the E-selectin-binding glycoform of PSGL-1 (CLA) on human skin-homing T cells, suggesting that 4-F-GlcNAc could impair the skin-homing phenotype of effector $\mathrm{T}$ cells and dampen cutaneous inflammation (18).

In this report, we initially investigated the effects of 4-F-GlcNAc on E- and P-selectin ligand expression synthesized by murine Th1 cells generated in vitro, to analyze the potential of preventing effector $T$ cell migration to inflamed skin. We show that 4-F-GlcNAc prevented de novo expression of E- and P-selectin ligands on Th1 cells comparable with low E- and P-selectin ligand expression on FucTVII-deficient Th1 cells. The lack of inhibition by swainsonine, which suppresses complex-type $N$-glycan formation, was consistent with prior data showing swainsonine's inability to modify selectin-binding activity on human $\mathrm{CLA}^{+} \mathrm{T}$ cells (18). Concentrations of 4-F-GlcNAc that were sufficient to ablate selectin ligand synthesis did not greatly influence the expression of the activation-dependent glycoform of CD43 and affected neither PSGL-1 polypeptide expression nor cell proliferation after $\mathrm{CD} 3$ stimulation. Though other effector $\mathrm{T}$ cell subsets, including $\mathrm{CD}^{+} \mathrm{T}$ cells, also synthesize selectin ligands and contribute to elicitation of CHS $(7,11,13,36)$, these data provide an experimental rationale for the proposed glycosylation-inhibitory effects of 4-F-GlcNAc on relevant effector T cells in allergic CHS.

We subsequently examined in vivo efficacy of 4-FGlcNAc in an antigen-dependent mouse model of cutaneous inflammation (CHS) in mice treated over a fivefold dose range of 4-F-GlcNAc. In these experiments, by varying drug-treatment schedules to coordinate with either afferent or efferent phases of CHS responses, we found that 4-F-GlcNAc treatment caused marked reductions in CHS inflammatory reactions by significantly impairing the elicitation phase and the ability of effector $\mathrm{CD}^{+} \mathrm{T}$ cells to enter the site of antigenic challenge. The level of 4-F-GlcNAc antiinflammatory activity was similar to the weak inflammatory responses observed in FucTIV/VII-deficient mice, whereas mice treated with the control drug GlcNAc exhibited robust CHS reactions. Interestingly, swainsonine-treated mice showed slightly higher CHS responses compared with inflammation in diluent control-treated mice. Because of the role of complex $\mathrm{N}$-glycans in the negative regulation of T cell activation (32), enhanced CHS responses in swainsoninetreated mice further indicated a clear role for $\mathrm{T}$ cell complex $\mathrm{N}$-glycans in suppressing and/or controlling $\mathrm{T}$ cell-mediated inflammatory states. The fact that 4-F-GlcNAc treatment during the antigen-sensitization phase, with a 6-day recovery period, was ineffective at lowering CHS suggests that 4-F-GlcNAc treatment did not cause antigenic tolerance through suppression of $\mathrm{T}$ cell activation during antigenic exposure. Further studies elucidating potential immunological perturbation by 4-F-GlcNAc will be needed to more fully characterize 4-F-GlcNAc effects on antigenic $T$ cell recognition and activation.

Analysis of E-selectin ligand expression on lymphocytes in LNs draining DNFB-sensitized skin clearly revealed that 4-F-GlcNAc targeted E-selectin ligand synthesis without affecting PSGL-1 polypeptide expression. Data also indicated that the primary glycoprotein carrier of effector lymphocyte E-selectin ligand activity comigrated with PSGL-1, represented by 120 - and $220-\mathrm{kDa}$-stained molecules, though there was an additional unknown glycoprotein at about 190 $\mathrm{kDa}$ bearing E-selectin ligand activity. Upregulation of the E-selectin-binding glycoform of PSGL-1 on lymphocytes upon antigenic stimulation directly correlated with induction of the skin-homing phenotype or the capacity to elicit a cutaneous inflammatory response. The absence of effector lymphocyte E-selectin ligand expression in FucTIV/VII-null mice and in mice treated with $100 \mathrm{mg} / \mathrm{kg}$ 4-F-GlcNAc resulted in a complete attenuation of CHS reactions in these mice. Though there was only a slight reduction in E-selectin ligand level in mice treated with $50 \mathrm{mg} / \mathrm{kg}$ 4-F-GlcNAc compared with untreated mice, this minor inhibition was sufficient to cause a statistically significant reduction in CHS response (by 75\%). Indeed, complete ablation of PSGL-1 selectin-binding activity, in vivo, is not required for potent anti-inflammatory action (37) and may help explain the antiinflammatory efficacy of $50 \mathrm{mg} / \mathrm{kg}$ 4-F-GlcNAc.

To further address the possibility of 4-F-GlcNAc affecting the sensitization phases of CHS, we investigated antigenic processing and presentation in LNs draining antigen-sensitized skin and the capacity of naive lymphocytes to adhere to skin-draining $\mathrm{LN}$ HEVs. Since the binding of L-selectin ${ }^{+}$lymphocytes to LN HEVs is dependent on the expression of 6-sulfo-sialyl Lewis X structures on the endothelial cells lining HEVs $(10,38,39)$, it was conceivable that 4-F-GlcNAc could have lowered 6-sulfo-sialyl Lewis X expression and prevented L-selectin-mediated lymphocyte binding to HEVs, thus preventing the entry of lymphocytes into the LNs. Furthermore, 4-F-GlcNAc could have modulated the expression of dermal hyaluronic acid (HA), a repeating (GlcNAc $\beta 1,4$ glucuronic acid $\beta 1,3)_{n}$ carbohydrate structure that binds CD44 on antigenpresenting LCs and facilitates LC migration to skindraining LNs $(40,41)$. Data from these studies suggested that 4-F-GlcNAc neither diminished L-selectinmediated lymphocyte adhesion to LN HEVs nor hindered antigenic processing and presentation in skindraining LNs. Collectively, these results indicate that 4F-GlcNAc action or poly- $N$-acetyllactosamine chain inhibition does not appear to affect HA synthesis or HEV L-selectin ligand synthesis, which is not dependent on poly- $N$-acetyllactosamine synthesis per se. Though $N$-acetyllactosamine disaccharides are necessary for HEV L-selectin ligand synthesis $(38,39)$, 4-F-GlcNAc 
incorporation into a growing poly- $N$-acetyllactosamine chain displayed by PSGL-1 on an activated $T$ cell is apparently more selective. In a related study supporting the importance of poly- $N$-acetyllactosamines in leukocyte trafficking, mice deficient in $\beta 1,4$ galactosyltransferase I exhibit a marked reduction $(80 \%)$ in poly$\mathrm{N}$-acetyllactosamines displayed by leukocyte core 2 O-glycans, and, while lymphocyte homing to peripheral LNs appears to be normal, leukocyte E- and P-selectin ligand synthesis and cutaneous inflammatory responses are defective (42). Considering the pharmacological potential of 4-F-GlcNAc as an anti-inflammatory therapeutic agent for suppression of cutaneous $\mathrm{T}$ cell-mediated inflammatory diseases, retention of immunological properties critical to acquired cellmediated immunity during 4-F-GlcNAc intervention would be beneficial.

It is clear that other adhesion molecules on effector leukocytes, including CD44 (43), $\beta 2$ integrins (35), and L-selectin (7), are also involved in the elicitation phase of an allergic CHS response. Since dermal endothelial HA and sialyl Lewis X structures are carbohydrate ligands for leukocyte CD44 and L-selectin, respectively $(41,44), 4-F-G l c N A c$ anti-inflammatory efficacy may have been due to the downregulation of dermal HA and sialyl Lewis X antigen expression. However, based on the lack of inhibitory effects of 4-F-GlcNAc on HEV L-selectin ligand activity and LC migration, we believe that the expression of both L-selectin ligands and HA on dermal vascular endothelium is not appreciably affected by 4-F-GlcNAc. The role of $\beta 2$ integrins in firm adhesion of leukocytes to endothelial surfaces following tethering and rolling events initiated by effector lymphocyte E- and P-selectin ligands is also important for entry into inflamed skin, although, as our data suggest, ablation of selectin ligands without downregulating CD18 expression on effector leukocytes due to 4-F-GlcNAc treatment is sufficient for prevention of dermal tropism. Although we did not observe differences in total blood cell counts or leukocyte-subset percentages from retro-orbital bleeds between untreated and 4-F-GlcNAc-treated mice (data not shown), further studies need to be performed to address concerns of altered leukocyte distribution in tissues, of homeostatic immune mechanisms, and of inflammatory responsiveness in other organ sites.

In conclusion, data from these studies strengthen the pharmacological view that modulation of the E-selectin-binding glycoform of PSGL-1 (CLA) can impair cutaneous inflammation (45-49). Downregulation of CLA expression on effector inflammatory leukocytes with 4-F-GlcNAc, in light of other promising studies demonstrating the efficacy of selectinselectin ligand interference and consequent inhibition of cutaneous inflammation warrants further preclinical exploration and clinical consideration. The unique expression of CLA on leukocytes associated with other skin-related diseases including psoriasis, atopic dermatitis, and cutaneous $\mathrm{T}$ cell lymphomas further implies the value of CLA as a therapeutic target to selectively modify skin-specific tropism (50).

\section{Acknowledgments}

We thank Benjamin Rich and Robert C. Fuhlbrigge (Department of Dermatology, Brigham and Women's Hospital) for helpful discussions on experimental approaches to evaluate 4-F-GlcNAc efficacy. In addition, we thank Derek Cain, Denise Long-Woodward, and Lisa Liu for their technical assistance, and Ralph J. Bernacki (Roswell Park Cancer Institute, Buffalo, New York, USA) for kindly providing 4-F-GlcNAc. This work was supported by NIH National Research Service Award CA91780-01 (to C.J. Dimitroff), National Cancer Institute grant RO1 CA84156 (to R. Sackstein), National Heart, Lung, and Blood Institute grant RO1 HL60528 (to R. Sackstein), and Harvard Skin Disease Research Center Core grant P30 AR42689 (to T.S. Kupper).

1. Borges, E., et al. 1997. P-selectin glycoprotein ligand-1 (PSGL-1) on T helper 1 but not on T helper 2 cells binds to P-selectin and supports migration into inflamed skin. J. Exp. Med. 185:573-578.

2. Hirata, T., et al. 2000. P-selectin glycoprotein ligand 1 (PSGL-1) is a physiological ligand for E-selectin in mediating $\mathrm{T}$ helper 1 lymphocyte migration. J. Exp. Med. 192:1669-1676.

3. Subramaniam, M., et al. 1995. Reduced recruitment of inflammatory cells in a contact hypersensitivity response in P-selectin-deficient mice. J. Exp. Med. 181:2277-2282.

4. Staite, N., Justen, J.M., Sly, L.M., Beaudet, A.L., and Bullard, D.C. 1996. Inhibition of delayed-type contact hypersensitivity in mice deficient in both E-selectin and P-selectin. Blood. 88:2973-2979.

5. Austrup, F., et al. 1997. P- and E-selectin mediate recruitment of T-helper1 but not T-helper-2 cells into inflamed tissues. Nature. 385:81-83.

6. Catalina, M.D., Estess, P., and Siegelman, M.H. 1999. Selective recruitments for leukocyte adhesion molecules in models of acute and chronic cutaneous inflammation: participation of E- and P- but not L-selectin. Blood. 93:580-589.

7. Hirata, T., Furie, B.C., and Furie, B. 2002. P-, E-, and L-selectin mediate migration of activated CD8+ $\mathrm{T}$ lymphocytes into inflamed skin. J. Immunol. 169:4307-4313.

8. Maly, P., et al. 1996. The alpha(1,3)fucosyltransferase Fuc-TVII controls leukocyte trafficking through an essential role in L-, E-, and P-selectin ligand biosynthesis. Cell. 86:643-653.

9. Weninger, W., et al. 2000. Specialized contributions by alpha(1,3)-fucosyltransferase-IV and FucT-VII during leukocyte rolling in dermal microvessels. Immunity. 12:665-676.

10. Homeister, J.W., et al. 2001. The alpha(1,3)fucosyltransferases FucT-IV and FucT-VII exert collaborative control over selectin-dependent leukocyte recruitment and lymphocyte homing. Immunity. 15:115-126.

11. Smithson, G., et al. 2001. FucTVII is required for T helper 1 and T cytotoxic 1 lymphocyte selectin ligand expression and recruitment in inflammation, and together with FucTIV regulates naïve T-cell trafficking to lymph nodes. J. Exp. Med. 194:601-614.

12. Blander, J.M., Visintin, I., Janeway, C.A., Jr., and Medzhitov, R. 1999. Alpha(1,3)-fucosyltransferase VII and alpha(2,3)-sialyltransferase IV are up-regulated in activated CD4 $\mathrm{T}$ cells and maintained after their differentiation into Th1 and migration into inflammatory sites. J. Immunol. 163:3746-3752.

13. Erdmann, I., et al. 2002. Fucosyltransferase VII-deficient mice with defective E-, P-, and L-selectin ligands show impaired CD4+ and CD8+ T cell migration into the skin, but normal extravasation into visceral organs. J. Immunol. 168:2139-2146.

14. Snapp, K.R., Heitzig, C.E., Ellies, L.G., Marth, J.D., and Kansas, G.S. 2001. Differential requirements for the O-linked branching enzyme core 2 beta1-6-N-glucosaminyltransferase in biosynthesis of ligands for E-selectin and P-selectin. Blood. 97:3806-3811.

15. White, S.J., Underhill, G.H., Kaplan, M.H., and Kansas, G.S. 2001. Cutting edge: differential requirements for Stat 4 in expression of glycosyltransferases responsible for selectin ligand formation in Th1 cells. J. Immunol. 167:628-631.

16. Lim, Y.C., et al. 2001. IL-12, STAT4-dependent up-regulation of CD4(+) T cell core 2 beta-1,6-N-acetylglucosaminyltransferase, an enzyme essential for biosynthesis of P-selectin ligands. J. Immunol. 167:4476-4484. 
17. Kumar, R., Camphausen, R.T., Sullivan, F.X., and Cumming, D.A. 1996 Core2 beta-1,6-N-acetylglucosaminyltransferase enzyme activity is critical for P-selectin glycoprotein ligand-1 binding to P-selectin. Blood. 88:3872-3879.

18. Dimitroff, C.J., Bernacki, R.J., and Sackstein, R. 2003. Glycosylationdependent inhibition of cutaneous lymphocyte-associated antigen: implications in modulating lymphocyte migration to skin. Blood. 101:602-610.

19. Picker, L.J., Michie, S.A., Rott, L.S., and Butcher, E.C. 1990. A unique phenotype of skin-associated lymphocytes in humans. Preferential expression of the HECA-452 epitope by benign and malignant $T$ cells at cutaneous sites. Am. J. Pathol. 136:1053-1068.

20. Berg, E.L., et al. 1991. The cutaneous lymphocyte antigen is a skin lymphocyte homing receptor for the vascular lectin endothelial cell-leukocyte adhesion molecule 1.J. Exp. Med. 174:1461-1466.

21. Fuhlbrigge, R.C., Kieffer, D., Armerding, D., and Kupper, T.S. 1997. Cutaneous lymphocyte antigen is a specialized form of PSGL-1 expressed on skin-homing T-cells. Nature. 389:978-981.

22. Woynarowska, B., et al. 1994. Inhibition of lectin-mediated ovarian tumor cell adhesion by sugar analogs. J. Biol. Chem. 69:22797-22803.

23. Woynarowska, B., et al. 1996. The effect of a 4-fluoro-glucosamine ana$\log$ on the adhesion of human colon carcinoma HT-29 cells. Glycoconj. J. 13:663-674.

24. Wagers, A.J., Waters, C.M., Stoolman, L.M., and Kansas, G.S. 1998. Interleukin 12 and interleukin 4 control $\mathrm{T}$ cell adhesion to endothelial selectins through opposite effects on alpha1, 3 fucosyltransferase VII gene expression. J. Exp. Med. 188:2225-2231.

25. Lim, Y.C., et al. 1999. Expression of functional selectin ligands on Th cells is differentially regulated by IL-12 and IL-4. J. Immunol. 162:3193-3201.

26. Oxley, S.M., and Sackstein, R. 1994. Detection of an L-selectin ligand on a hematopoietic progenitor cell line. Blood. 84:3299-3306.

27. Dimitroff, C.J., Lee, J.Y., Schor, K., Sandmaier, B., and Sackstein, R. 2001. Differential L-selectin binding activities of human hematopoietic cell L-selectin ligands, HCELL and PSGL-1. J. Biol. Chem. 276:47623-47631.

28. Sharma, M., Bernacki, R.J., and Korytnyk, W. 1988. Fluorinated carbohydrates: chemical and biochemical aspects. American Chemical Society Symposium Series no. 374. Chapter 11, 191-206.

29. Sharma, M., Bernacki, R.J., Paul, B., and Korytnyk, W. 1990. Fluorinated carbohydrates as potential plasma membrane modifiers. Synthesis of 4- and 6-fluoro derivatives of 2-acetamido-2-deoxy-D-hexopyranoses. Carbohydr. Res. 198:205-221.

30. Dimitroff, C.J., Sharma, A., and Bernacki, R.J. 1998. Cancer metastasis: a search for therapeutic inhibition. Cancer Invest. 16:279-290.

31. Dennis, J.W., Koch, K., Yousefi, S., and VanderElst, I. 1990. Growth inhibition of human melanoma tumor xenografts in athymic nude mice by swainsonine. Cancer Res. 50:1867-1872.

32. Demetriou, M., Granovsky, M., Quaggin, S., and Dennis, J.W. 2001. Negative regulation of T-cell activation and autoimmunity by Mgat $5 \mathrm{~N}$-glycosylation. Nature. 409:733-739.

33. Tietz, W., et al. 1998. CD4+ T-cells migrate into inflamed skin only if they express ligands for E- and P-selectin. J. Immunol. 161:963-970.
34. Grabbe, S., and Schwarz, T. 1998. Immunoregulatory mechanisms involved in elicitation of allergic contact hypersensitivity. Immunol. Today. 19:37-44.

35. Grabbe, S., et al. 2002. $\beta 2$ integrins are required for skin homing of primed $\mathrm{T}$ cells but not for priming naive $\mathrm{T}$ cells. J. Clin. Invest. 109:183-192. doi:10.1172/JCI200211703.

36. Gocinski, B.L., and Tigelaar, R.E. 1990. Roles of CD4+ and CD8+ T cells in murine contact sensitivity revealed by in vivo monoclonal antibody depletion. J. Immunol. 144:4121-4128.

37. Hicks, A.E., Nolan, S.L., Ridger, V.C., Hellewell, P.G., and Norman, K.E. 2003. Recombinant P-selectin glycoprotein ligand-1 directly inhibits leukocyte rolling by all 3 selectins in vivo: complete inhibition of rolling is not required for anti-inflammatory effect. Blood. 101:3249-3256.

38. Mitsuoka, C., et al. 1998. Identification of a major carbohydrate capping group of the L-selectin ligand on high endothelial venules in human lymph nodes as 6-sulfo sialyl Lewis X. J. Biol. Chem. 273:11225-11233.

39. Yeh, J.C., et al. 2001. Novel sulfated lymphocyte homing receptors and their control by a Core 1 extension beta $1,3-\mathrm{N}$-acetylglucosaminyltransferase. Cell. 105:957-969.

40. Weiss, J.M., et al. 1997. An essential role for CD44 variant isoforms in epidermal Langerhans cell and blood dendritic cell function. J. Cell Biol. 137:1137-1147.

41. Mummert, M.E., Mohamadzadeh, M., Mummert, D.I., Mizumoto, N., and Takashima, A. 2000. Development of a peptide inhibitor of hyaluronan-mediated leukocyte trafficking. J. Exp. Med. 192:769-779.

42. Asano, M., et al. 2003. Impaired selectin ligand biosynthesis and reduced inflammatory responses in $\beta$-1,4-galactosyltransferase-I-deficient mice. Blood. 102:1678-1685.

43. Camp, R.L., Scheynius, A., Johansson, C., and Pure, E. 1993. CD44 is necessary for optimal contact allergic responses but is not required for normal leukocyte extravasation. J. Exp. Med. 178:497-507.

44. Tu, L., Delahunty, M.D., Ding, H., Luscinskas, F.W., and Tedder, T.F. 1999. The cutaneous lymphocyte antigen is an essential component of the L-selectin ligand induced on human vascular endothelial cells. J. Exp. Med. 189:241-252.

45. Boehncke, W.H., and Schon, M.P. 2003. Interfering with leukocyte rolling: a promising therapeutic approach in inflammatory skin disorders? Trends Pharmacol. Sci. 24:49-52.

46. Schottelius, A.J., Hamann, A., and Asadullah, K. 2003. Role of fucosyltransferases in leukocyte trafficking: major impact for cutaneous immunity. Trends Immunol. 24:101-104.

47. Biedermann, T., et al. 2002. Targeting CLA/E-selectin interactions prevents CCR4-mediated recruitment of human Th2 memory cells to human skin in vivo. Eur. J. Immunol. 32:3171-3180.

48. Norman, K.E., Anderson, G.P., Kolb, H.C., Ley, K., and Ernst, B. 1998. Sialyl Lewis(x) (sLe(x)) and an sLe(x) mimetic, CGP69669A, disrupt E-selectin-dependent leukocyte rolling in vivo. Blood. 91:475-483.

49. Schon, M.P., et al. 2002. Efomycine M, a new specific inhibitor of selectin, impairs leukocyte adhesion and alleviates cutaneous inflammation. Nat. Med. 8:366-372.

50. Robert, C., and Kupper, T.S. 1999. Inflammatory skin diseases, T cells, and immune surveillance. N. Engl.J. Med. 341:1817-1828. 